\title{
Avaliação da intensidade de contaminação de pontas de seringa tríplice
}

\section{Evaluation of the bacterial contamination of air/water syringes tips}

\author{
Eliza Maria Agueda RUSSO* \\ Rubens Côrte Real de CARVALHO** \\ José Luiz de LORENZO*** \\ Narciso GARONE NETTO**** \\ Marcio Vivan CARDOSO $* * * * *$ \\ Eric GROSSI*****
}

\begin{abstract}
RUSSO, E. M. A.; CARVALHO, R. C. R. de; LOREnZO, J. L. de; GARONE NETTO, N.; CARDOSO, M. V.; GROSSI, E. Avaliação da intensidade de contaminação de pontas de seringa tríplice. Pesqui Odontol Bras, v. 14, n. 3, p. 243-247, jul./set. 2000.

O controle de infecção cruzada em consultórios odontológicos inclui cuidados especiais com as seringas tríplices. Os autores pesquisaram a intensidade de contaminação pela microbiota bucal, de pontas de seringas tríplices usadas no atendimento a pacientes de Dentística Restauradora. Cinqüenta pontas descartáveis (Riskcontrol, Injecta Prod. Odontológicos) foram avaliadas: 10, imediatamente após a abertura da embalagem; 30, após o uso em pacientes; e 10, após o uso e a desinfecção com álcool etílico $70 \% \mathrm{P} / \mathrm{V}$, friccionado por um minuto. Em câmara de fluxo laminar, as pontas foram "roladas" sobre a superficie de Tryptic Soy Agar, suplementado com 5\% de sangue desfibrinado de carneiro. Após 96 horas de incubação anaeróbia, foi feita a avaliação da quantidade de unidades formadoras de colônias (ufc) desenvolvidas. Confirmando a informação do fabricante, as pontas estavam estéreis quando retiradas da embalagem. Em todas as pontas usadas em pacientes, observou-se um número incontável de ufc (maior que 300), revelando intensa contaminação. Nas pontas usadas e desinfetadas com álcool etílico $70 \% \mathrm{P} / \mathrm{V}$, verificou-se apreciável redução na contagem de colônias (1 a 100 ufc), mas incompativel com a segurança biológica. Os resultados sugerem, como condição ideal, o uso de pontas descartáveis nas seringas tríplices.
\end{abstract}

UNITERMOS: Controle de infecção; Infecção cruzada; Contaminação microbiana.

\section{INTRODUÇÃO}

O aumento da incidência de doenças transmissiveis graves, nas últimas décadas, obrigou a uma conscientização geral sobre os riscos de contaminação e modificou os hábitos dos profissionais nas clínicas odontológicas.

Além dos virus HIV e os da hepatite B, C e D, outras moléstias infecciosas transmissiveis, como mononucleose, herpes simples I e II e tuberculose, hoje são reconhecidas como uma ameaça constante para os profissionais de Odontologia e seus pacientes $^{1,5,9,17}$.

As questões relativas ao controle de infecção e às normas de biossegurança passaram assim a ter novo enfoque, já que não eram vistas de forma tão crítica como são agora.

Muitos recursos para evitar a ocorrência de infecções cruzadas em consultórios odontológicos têm sido recomendados. Entretanto, qualquer negligência pode intensificar a incidência dessas infecções ${ }^{3,11}$.

Dessa forma, organizações de saúde do mundo inteiro - como o Center for Disease Control $\left(\mathrm{CDC}^{6,7}\right)$ e a American Dental Association ( $\left.\mathrm{ADA}^{1}\right)$, entre outras - têm desenvolvido normas de assepsia, desinfecção e esterilização, preconizando a adoção de um protocolo de controle da infecção $0^{2,10}$.

Segundo SCHAEFER ${ }^{16}$, essas normas são universais porque devem ser aplicadas a todos os pa-

* Professora Doutora; ** Professor Livre-Docente; **** Professor Titular; ***** Estagiários Didáticos - Departamento de Dentística da Faculdade de Odontologia da USP.

*** Professor Doutor do Departamento de Microbiologia do Instituto de Ciências Biológicas da USP. 
RUSSO, E. M. A.; CARVAlhO, R. C. R. de; LOREnZO, J. L. de; GARONE NETTO, N.; CARDOSO, M. V.; GROSSI, E. Avaliação da intensidade de contaminação de pontas de seringa tríplice. Pesqui Odontol Bras, v. 14, n. 3, p. 243-247, jul./set. 2000.

cientes, em todos os tipos de tratamento odontológico e para todos os instrumentos e equipamentos.

Os protocolos propostos atribuem ênfase especial às barreiras de proteção contra microrganismos. Para os profissionais da saúde, recomendam o uso de avental, gorro, óculos, luvas e máscaras descartáveis. Para as pontas e certas superfícies (o encosto de cabeça, por exemplo), indicam o recobrimento com filmes plásticos, trocados no intervalo de cada atendimento. O número de partículas microbianas suspensas no ar pode ser reduzido pelo uso de dique de borracha, associado a sugador de alta potência ${ }^{8,13}$.

Outro procedimento indicado é o bochecho com solução anti-séptica, como o digluconato de clorexidina a $0,12 \%$, a ser feito pelo paciente antes de iniciar qualquer tipo de intervenção.

Mesmo com todos esses cuidados, a segurança não é completa.

Os aerossóis altamente contaminados, gerados quando do acionamento das turbinas de alta rotação e de seringas triplices, permanecem um problema de dificil solução.

Quando as seringas triplices e as canetas de alta rotação são acionadas, ocorre, por uma fração de segundo, um refluxo capaz de contaminar o interior desses equipamentos ${ }^{4,6,15,18,19}$. Uma vez contaminada, a superfície do lúmen do equipamento pode atuar como um reservatório, facilitando a contínua recontaminação.

Atualmente, as canetas de alta e baixa rotação são autoclaváveis. Porém, um grande número de profissionais não possui esses modelos, o que impede a correta esterilização desse equipamento.

No caso das seringas triplices, existe controvérsia sobre a efetividade de desinfecção das mesmas. Para o Council on Scientific Affairs e o Council on Dental, ambos da $\mathrm{ADA}^{2}$, o emprego de pontas de seringa tríplice removiveis, descartáveis, exclusivas para cada paciente, constitui o procedimento mais apropriado.

Preocupados com a possibilidade de ocorrência de infecções cruzadas e, ao mesmo tempo, cientes das dificuldades de desinfecção das pontas de seringa tríplice e das limitações dos recursos hoje utilizados (o recobrimento da ponta com tubo plástico descartável, por exemplo), propusemo-nos a verificar o grau de contaminação de pontas de seringa triplice estéreis, descartáveis, empregadas durante os procedimentos de preparo cavitário da Dentística Restauradora.

\section{MATERIAL E MÉTODOS}

Cinqüenta pontas de seringa tríplice descartáveis* foram submetidas à análise microbiológica: 30, imediatamente após a utilização em pacientes; 10, após o uso em pacientes e a desinfecção com álcool etílico $70 \% \mathrm{P} / \mathrm{V}$, friccionado por um minuto; e 10, sem uso, imediatamente após a abertura da embalagem.

Optou-se pelo uso dessas pontas descartáveis devido a seu tamanho e formato, que facilitaram o processamento microbiológico, e, sobretudo, por serem previamente esterilizadas, segundo o fabricante.

As pontas foram utilizadas durante o atendimento aos pacientes da Clínica de Dentística Restauradora da Faculdade de Odontologia da Universidade de São Paulo (FOUSP).

Em todos os casos, a ponta foi desembalada e acoplada ao adaptador inserido no corpo da seringa tríplice sempre com a proteção de luvas esterilizadas.

Durante o atendimento, a seringa tríplice foi acionada no interior da boca do paciente quantas vezes foram necessárias para viabilizar os procedimentos operatórios - que envolviam exame clínico, preparo cavitário, remoção do tecido cariado, proteção do complexo dentina-polpa e restauração.

No final de cada atendimento, a ponta foi removida, também com luvas esterilizadas, e, sob a proteção da chama de uma lamparina a álcool, depositada no interior de um tubo esterilizado de vidro, e imediatamente conduzida ao Laboratório de Microbiologia Oral do Instituto de Ciências Biomédicas da USP.

Em condições de assepsia (câmara de fluxo laminar), cada ponta foi retirada do tubo por meio de pinça esterilizada e sua ponta de adaptação, mais volumosa, cortada com tesoura esterilizada.

Para verificar a intensidade de contaminação bacteriana, executamos pequenas modificações na técnica de MAKI; WEISE; SARAFIN ${ }^{12}$, idealizada para avaliar o grau de contaminação de catéteres intravenosos suspeitos de estarem causando bacteriemias ou septicemias. A escolha dessa técnica fundamentou-se principalmente na forma cilindrica dos catéteres e das pontas de seringas triplices.

* Riskcontrol, Injecta Prod. Odontológicos. 
RUSSO, E. M. A.; CARVAlHO, R. C. R. de; LORENZO, J. L. de; GARONE NETTO, N.; CARDOSO, M. V.; GROSSI, E. Avaliação da intensidade de contaminação de pontas de seringa tríplice. Pesqui Odontol Bras, v. 14, n. 3, p. 243-247, jul./set. 2000.

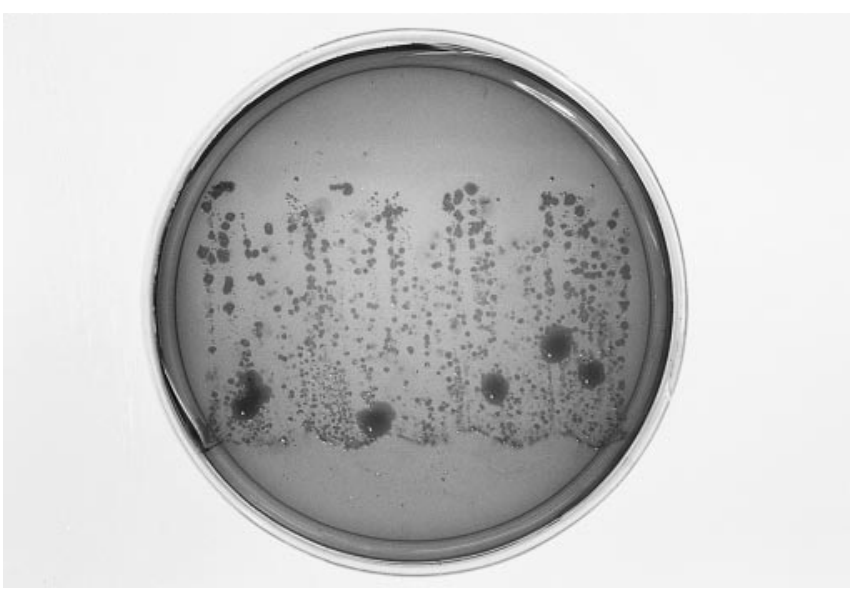

FIGURA 1 - Desenvolvimento bacteriano após o uso da ponta da seringa tríplice em um único paciente.

Cada ponta plástica descartável foi depositada na extremidade de uma placa de Petri contendo o meio Tryptic Soy Agar (TSA)*, suplementado com $5 \%$ de sangue desfibrinado de carneiro; esse meio é favorável ao cultivo de bactérias de dificil desenvolvimento.

Por meio de uma pinça esterilizada, a ponta foi então "rolada" sobre a superficie do ágar, de modo a permitir a remoção e a adesão, no meio de cultura, das bactérias que contaminavam a ponta plástica descartável.

A incubação das placas foi realizada em jarras de anaerobiose, obtida através do sistema Gaspak $^{* *}$, durante 96 horas, com a finalidade de detectarmos o desenvolvimento tanto de anaeróbios facultativos como de estritos, que constituem praticamente a totalidade da microbiota bucal. Após a incubação foi efetuada, quando possivel, a contagem de unidades formadoras de colônias (ufc) desenvolvidas na superficie semeada do ágar.

Da mesma forma pesquisou-se a eficácia da desinfecção de 10 pontas descartáveis, após o uso clínico, por meio de álcool etílico $70 \% \mathrm{P} / \mathrm{V}$, friccionado por um minuto. A mesma metodologia bacteriológica foi ainda utilizada para testar a condição prévia de esterilidade das pontas plásticas descartáveis.

\section{RESULTADOS}

As pontas sem uso, analisadas imediatamente após a abertura da embalagem, não apresentaram

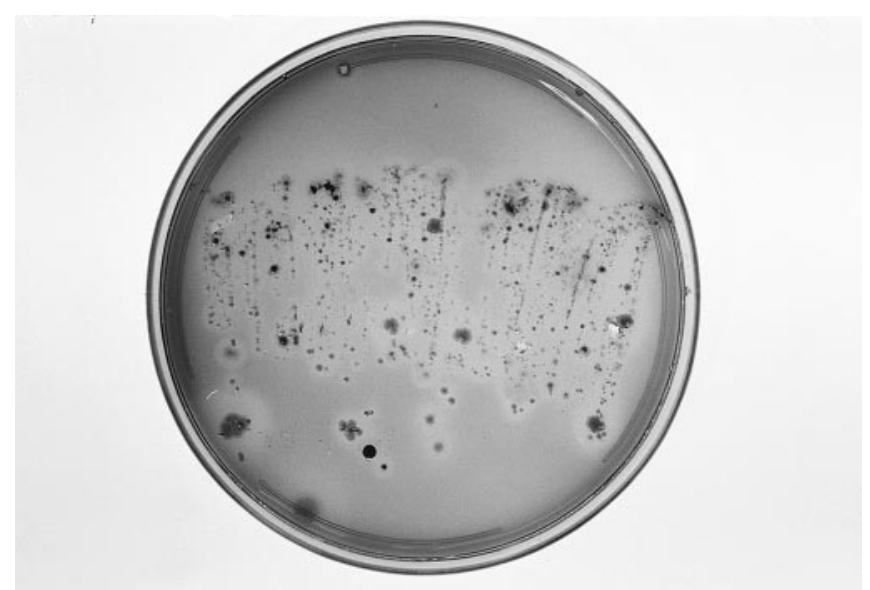

FIGURA 2 - Desenvolvimento bacteriano após desinfecção da ponta da seringa tríplice com álcool etílico $70 \%$ $\mathrm{P} / \mathrm{V}$ (placa que apresentou o maior número de ufc, nesse grupo).

desenvolvimento de colônias de bactérias, o que representa 0 (zero) ufc. Esse resultado mostra que, antes do uso, encontravam-se devidamente esterilizadas.

No caso das pontas que, após serem utilizadas em pacientes, sofreram desinfecção com álcool etílico $70 \% \mathrm{P} / \mathrm{V}$, registrou-se crescimentos variando de 1 a 100 ufc, nas diferentes amostras analisadas.

Em todas as 30 pontas analisadas imediatamente após a utilização em pacientes, constatou-se um desenvolvimento maciço e, conseqüentemente, incontável de ufc bacterianas, revelando intenso grau de contaminação (número de ufc > que 300) (Figuras 1 e 2).

\section{DISCUSSÃO}

A análise microbiológica demonstrou que as pontas de seringa tríplice descartáveis estavam previamente esterilizadas, confirmando a informação do fabricante. Na clínica, quando utilizadas, foram manipuladas sempre com luvas esterilizadas e serviram, cada uma, a apenas um paciente. No laboratório, todos os cuidados para não contaminação também foram tomados. No entanto, acabamos encontrando uma grande quantidade de bactérias facultativas e anaeróbias depositadas em cada ponta usada (> 300 ufc).

Considerando esses fatos, parece evidente que o alto grau de contaminação observado teve origem unicamente no uso da seringa tríplice, a partir do

* Biobrás - Bioquímica do Brasil S. A.

** BBL, Becton Dickinson, EUA. 
RUSSO, E. M. A.; CARVAlHO, R. C. R. de; LORENZO, J. L. de; GARONE NETTO, N.; CARDOSO, M. V.; GROSSI, E. Avaliação da intensidade de contaminação de pontas de seringa tríplice. Pesqui Odontol Bras, v. 14, n. 3, p. 243-247, jul./set. 2000.

contato da ponta descartável com as bactérias presentes na boca do paciente, durante os procedimentos operatórios.

A fricção com álcool etílico $70 \% \mathrm{P} / \mathrm{V}$ por um minuto resultou em intensidades de contaminação bacteriana menores do que as encontradas sem nenhum tipo de desinfecção (1 a 100 ufc). Mas, como uma única colônia de bactérias já pode provocar infecção cruzada, esses resultados não podem ser qualificados como aceitáveis.

É importante ressaltar que as pontas descartáveis apresentam menos reentrâncias do que as pontas metálicas usualmente utilizadas. Pressupondo que essas reentrâncias retenham maior número de microrganismos, podemos deduzir que, nas pontas metálicas, o grau de contaminação seria ainda maior do que o registrado no presente estudo. Isso, sem contar o já mencionado problema do refluxo e conseqüente contaminação da superfície do lúmen do equipamento ${ }^{4,6,14,18,19,20}$.

Dessa forma, a conveniência da utilização das pontas descartáveis, substituídas após o uso em cada paciente, ganha relevo. Embora não anule a possibilidade de adoção de um outro recurso: a esterilização das pontas metálicas das seringas tríplices por meio de autoclaves ou de estufas esterilizadoras. O uso da autoclave e do calor seco são meios comprovadamente efetivos na esterilização de instrumentos e equipamentos.

Contudo, diante do pequeno número de profissionais que dispõe de seringas tríplices autoclaváveis e de autoclave em seus consultórios, parece lícito sugerir a utilização de pontas descartáveis nas seringas triplices, com troca após o uso em cada paciente, como forma de evitar a possibilidade de infecção cruzada.

Esta sugestão, baseada nos resultados obtidos neste trabalho, coincide com as recomendações para controle de infecção em consultórios dentários (ADA - Council on Scientific Affairs and ADA Council on Dental Practice ${ }^{2}$ ), entre as quais se inclui o emprego de pontas descartáveis para as seringas triplices, utilizadas uma para cada paciente.

\section{CONCLUSÕES}

Diante dos dados obtidos, podemos concluir que:

1. apenas um procedimento operatório, em um único paciente, é suficiente para promover alta contaminação da ponta da seringa tríplice (número de ufc > 300);

2. a desinfecção com álcool etílico $70 \%$ P/V não é um método aceitável, pois não impediu o desenvolvimento bacteriano em nenhuma das amostras testadas (número de ufc $=1$ a 100);

3. as pontas de seringa tríplice descartáveis estavam previamente esterilizadas (número de ufc $=0$ ), confirmando a informação do fabricante;

4. o emprego de pontas removiveis e descartáveis nas seringas tríplices, desde que trocadas após o uso em cada paciente, pode ser considerado um método seguro para o controle da infecção cruzada.

RUSSO, E. M. A.; CARVAlHO, R. C. R. de; LOREnZO, J. L. de; GARONE NETTO, N.; CARDOSO, M. V.; GROSSI, E. Evaluation of bacterial contamination of air/water syringes tips. Pesqui Odontol Bras, v. 14, n. 3, p. 243-247, jul./set. 2000.

Effective infection control procedures to prevent cross-contamination in the dental office include care with air/water syringes. The authors had the purpose to verify the bacterial contamination of air/water syringes used in patients seen at the Restorative Dental Clinic, School of Dentistry, University of São Paulo, Brazil. Fifty disposable tips (Riskcontrol, Injecta Prod. Odontológicos) were analysed: 10, immediately after the package was opened; 10, after a single use followed by disinfection with $70 \%$ alcohol for one minute; 30, after a single use without any posterior disinfection. The samples were transported to the laboratory and, under aseptic condition, rolled and compressed on a Tryptic Soy Agar surface with $5 \%$ of defibrillated sheep blood. After a 96-hour incubation, the reading was carried out with the help of a lens. According to the manufacture's information, the disposable tips were sterilized. In all of the tips used in patients, an uncountable amount of cfu (colony formation units) was found, revealing great contamination. In the disposable tips disinfected after being used, there was small bacterial growth, but that was incompatible with cross-contamination prevention. Therefore, we conclude that disposable air/water syringes tips must have a single use.

UNITERMS: Infection control; Cross-contamination; Microbial contamination. 
RUSSO, E. M. A.; CARVAlHO, R. C. R. de; LORENZO, J. L. de; GARONE NETTO, N.; CARDOSO, M. V.; GROSSI, E. Avaliação da intensidade de contaminação de pontas de seringa tríplice. Pesqui Odontol Bras, v. 14, n. 3, p. 243-247, jul./set. 2000.

\section{REFERÊNCIAS BIBLIOGRÁFICAS}

1. AMERICAN DENTAL ASSOCIATION. Infection control for the dental office and dental laboratory. J Am Dent Assoc, v. 123, p. 1-8, Aug. 1992. Suplemento.

2. AMERICAN DENTAL ASSOCIATION. Infection control recommendations for the dental office and the dental laboratory. J Am Dent Assoc, v. 127, n. 5, p. 672-680, May 1996.

3. AUTIO, K. K. Studies on cross-contamination in the dental office. J Am Dent Assoc, v. 100, n. 3, p. 358-362, 1980.

4. BÖSSMANN, K. Hygienic maintenance of dental handpieces and turbines. J Dent Assoc S Afr, v. 50, n. 9, p. 416-417, Sept. 1995 .

5. CENTERS FOR DISEASE CONTROL. Guidelines for preventing transmission of tuberculosis in health-care settings, with special focus on HIV related issues. MMWR, v. 39 (RR17), n. 1, p. 29, 1990.

6. CENTERS FOR DISEASE CONTROL. Measles on a college campus. Ohio: MMWR, v. 34, n. 7, p. 89-90, 1985.

7. CENTERS FOR DISEASE CONTROL AND PREVENTION. Update: recommended infection - control practices for dentistry. MMWR, v. 142 (RR8), p. 1-12, 1993.

8. COCHRAN, M. A; MILLER, C. H.; SHELDRAKE, M. A. The efficiency of the rubber dam as a barrier to the spread of microorganisms during dental treatment. J Am Dent Assoc, v. 119, p. 141-144, 1989.

9. COTTONE, J. A. Recent developments in hepatitis: new virus, vaccine and dosage recommendations. J Am Dent Assoc, v. 120, p. 501-508, 1990.

10. COUNCIL ON DENTAL THERAPEUTICS, COUNCIL ON DENTAL PRACTICE, COUNCIL ON DENTAL MATERIALS. Instruments and Equipment: infection control recommendations for the dental office and dental laboratory. J Am Dent Assoc, v. 116, p. 242-248, 1988.

11. CRAWFORD, J. J.; BRODERIUS, C. Control of cross infec- tion risks in the dental operatory: prevention of water retration by bur cooling spray systems. J Am Dent Assoc, v. 116, p. 687-695, 1988.

12. MAKI, D. G.; WEISE, C. E.; SARAFIN, H. W. A semi-quantitative culture method for identifying intravenous catheter-related infection. N Engl J Med, v. 296, p. 1305, 1977.

13. MILLER, R. L.; MICIK, R. E. Air pollution and its control in the dental office. Dent Clin North Amer, v. 22, p. 453, 1978.

14. PETERS, E.; McGAW, W. T. Dental unit water contamination. J Com Dent Assoc, v. 62, n. 6, p. 492-495, 1996.

15. SAMARANAYAKE, L. Handpiece and water line decontamination and HIV transmission: a critique. Dent Update, v. 20, n. 2, p. 53-56, Mar. 1993.

16. SCHAEFER, M. E. Infection control. Dealing with the special patient. J Calif Dent Assoc, v. 22, n. 8, p. 20-24, Aug. 1994.

17. THOMAS, L. E.; SYDSKIS, R. J.; DEVORE, D. T.; KRYWOLAP, G. N. Survival of herpes simplex and other selected microorganisms on patient charts: potential source of infection. J Am Dent Assoc, v. 111, p. 462-464, 1985.

18. WAGGONER, M. B. The New CDC surgical water recommendations: why they should be implemented and what they require. Compend Contin Educ Dent, v. 17, n. 6, p. 612-620, 1996.

19. WILLIAMS, H. N.; JONSSON, A.; KELLEY, J. I.; BAEWR, M. L.; KING, T. S.; MITCHEL, B.; HASLER, J. F. Bacterial contamination of the water supply in newly installed dental units. Quintessence Int, v. 26, n. 5, p. 331-337, May 1995.

20. WILLIAMS, J. F.; ANDREWS, N.; SANTIAGO, J. I. Microbial contamination of dental unit waterlines: current preventive measures and emerging options. Compend Contin Educ Dent, v. 17, n. 7, p. 691-698, July 1996.
Recebido para publicação em 15/09/99 Enviado para reformulação em 08/11/99 Aceito para publicação em 19/01/00 